\title{
Research Paper: Investigating Ethical Skills in Dentists and Dental Students: A Comparative Study
}

\author{
Sahar Vardian Tehrani ${ }^{1}$, Shabnam Bazmi ${ }^{2 *}$ \\ 1.School of Dentistry, Shahid Beheshti University of Medical Sciences, Tehran, Iran. \\ 2. Department of Medical Ethics, School of Traditional Medicine, Shahid Beheshti University of Medical Sciences, Tehran, Iran.
}

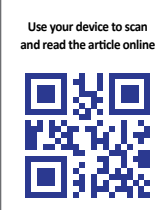

Citation: Vardian Tehrani S, Bazmi S. Investigating Ethical Skills in Dentists and Dental Students: A Comparative Study. International Journal of Medical Toxicology and Forensic Medicine. 2020; 10(3):27149. https://doi.org/10.32598/ijmtfm. v10i3.27149

https://doi.org/10.32598/ijmtfm.v10i3.27149

Keywords:

Professional ethics, Dentists,

Dental students

\section{ABSTRACT}

Background: Commitment to professional ethics is important for all medical practitioners, including dentists. This skill should be taught to students during their studies. The present study aimed to investigate moral skills in dental students and dentists.

Methods: This cross-sectional study was performed on 160 dental students and dentists. The Moral Skills Inventory (MSI) was cross-culturally adapted and used in this research. The MSI was developed by Chambers and has 40 items covering 4 domains; moral sensitivity, moral reasoning, moral integrity, and moral courage. Each domain's scores range from zero to 20 The obtained results were analyzed using SPSS.

Results: Compared to dentists, dental students achieved higher mean \pm SD scores in moral sensitivity (5.5 \pm 3.64 vs. $3.87 \pm 2.22)$ and moral integrity ( $6.4 \pm 3.2$ vs. $5.78 \pm 2.72)$ domains. However, in moral reasoning, dentists obtained higher mean \pm SD scores than students (15.40 \pm 2.11 vs. $13.92 \pm 2.35)$. In the moral courage domain, students' and dentists' scores were $13.47 \pm 3.10$ and $13.62 \pm 2.96$, respectively. The total mean \pm SD score of moral skills in all domains was calculated as $39.3 \pm 4.50$ for dental students, $38.68 \pm 4.48$ for dentists, and $38.99 \pm 4.49$ for all study participants.

Conclusion: The professional ethics skills were relatively poor in all 4 domains among the explored dental students and dentists. Workshops, reviewing the syllables of the medical ethics course, and practicing moral skills during training courses and monitoring professional performance could help to improve moral skills in this population.

\section{Introduction}

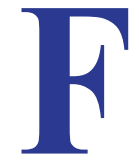

or more than 25 years, professional ethics has been a major topic in medical education. Besides, exploring this field has been among the priorities of medical research in the past two decades [1]. Professional ethics is a set of moral principles that individuals need to follow per their inner voice and conscience when performing professional activities, even without any external requirements and legal penalties [2].

Medical ethics is part of professional ethics that describes the ethical standards for medical practitioners.

* Corresponding Author:

Shabnam Bazmi, PhD.

Address: Department of Medical Ethics, School of Traditional Medicine, Shahid Beheshti University of Medical Sciences, Tehran, Iran.

Tel: +98 (912) 2575330

E-mail:sh_bazmi2003@yahoo.com 
In dentistry, similar to other medical disciplines, it is essential to properly communicate with patients. It is also critical to observe ethics and professional commitment in all aspects of work in this area. In other words, the moral competence of dentists comprises effective communication with patients, active listening to the patients' needs and requests, gathering information to correctly diagnose the condition, and presenting appropriate treatment plans, empathizing with the patient, and observing the principles of professional ethics and patients' rights [3].

In his book entitled "Beyond Illness", Larry Dossey states that in modern society, physicians mainly focus on the physical dimension or the patients' body and neglect the other two fundamental dimensions, i.e., the soul and mind; while the patient should be viewed as a whole. According to him, the best gift from physicians to their patients is to devote time to listening to the patient [4].

In Iran, the medical ethics course is compulsory in the curriculum of the dentistry program. Moreover, it is taught to students in the general dentistry program for several years. As clinical experience increases, the professional commitment must progress to the same extent. Therefore, the present study aimed to evaluate and compare commitment to ethics among dental students and graduates.

The four-component model of moral development is commonly used in dental studies, which helps to understand the moral functioning. James Rest et al. (1973) devised a measure of moral development with 4 items of moral sensitivity, moral reasoning, moral integrity, and moral courage. Based on these domains, a 40-item questionnaire, called the Moral Skill Inventory (MSI), was developed by Chambers in 2011. The developer considers it as a scoring tool and believes that it could be used to evaluate the 4 domains of Rest's model (moral sensitivity, moral reasoning, moral integrity, \& moral courage). In the following, we summarized the definition of each of these 4 items.

Moral sensitivity indicates the interpretation of situations from others' viewpoints; diagnosing the best ethical response in that situation, and the sensitivity to the feelings and reactions of others. In other words, it is the ability to observe an ethical dilemma, including how our actions affect others.

Moral reasoning or moral judgment suggests understanding the existing ethical challenge; adopting $f$ the best moral decision to resolve the challenge created in a particular situation, or the ability to reason correctly about what is 'ought' to be conducted in a specific condition.

Moral integrity is the ability to hold oneself to consistent moral and ethical standards and making the right ethical decision while facing the same conditions. A moral integrity deficit occurs when personal values or interests interfere with professional obligations and make it difficult to determine the correctness of a decision; therefore, it is fundamental to behavior that governs consistent actions of love towards others [5, 6] Moral courage indicates acting based on ethical values, despite the difficulties and harms of moral challenges and dilemmas [7].

Chambers believes that moral skills are aggregable in these 4 areas. He emphasizes on the familiarity of students with ethical skills. He also states that students should have the opportunity to judge particular cases and should be exposed to essential decisions and roles. Dental students are expected to be able to analyze complex moral situations and integrate these values into their practical work; they also must be able to demonstrate ethical behavior and work in these situations [5]. This research measured the moral skills of dental students and graduates. For this purpose, we employed a crossculturally adapted questionnaire of Chambers.

\section{Materials and Methods}

In total, 80 dental students from Shahid Beheshti University of Medical Sciences who were registered in the last 2 years of the dentistry program and 80 graduates were selected by simple random sampling method. This cross-sectional study was conducted during the academic year of 2016-2017. The sample size was determined by a statistician's opinion and using the following formula. 80: $4=20=$ SD

$$
n=\frac{\left(z_{1-a / 2}+z_{1}-\beta\right)^{2}\left(\sigma_{1}^{2}+\sigma_{2}{ }_{2}\right)}{\left(\mu_{1}-\mu_{2}\right)^{2}}=\frac{(1.96+1.2)^{2} \times 20^{2}}{100}=79.88 \sim 80
$$

( $\alpha=0.05$ and $\beta=0.1$, and the minimum difference of 10 units in the sum of scores between the two groups of students and graduates was considered significant. Therefore, considering $\mathrm{SD}=20,80$ participants were required.) The questionnaire consisted of two parts; the first part contained demographic information, and the second part included 40 specific questions in the areas of ethical skill. Initially, explanations about the research and the necessity of conducting it were given to the study participants. Accordingly, appropriate answers were provided to the 
study participants' potential questions. After receiving the study participants' consent, the questionnaire was completed. The confidentiality of the participants' information was considered in all stages of this study. This project was approved by Shahid Beheshti University of Medical Sciences Ethics Committee (Code: IR.SBMU. RETECH.REC.1398.020).

Overall, 10 questions were asked for each domain of moral sensitivity, moral reasoning, moral integrity, and moral courage (total: 40 questions). The total score ranged between 0 and 80 . The measurement tool was Chambers's main questionnaire, which has been translated into Persian and culturally-adapted on the Iranian population. Furthermore, its psychometric properties (validity \& reliability) were tested [8]. The CVI of the questionnaire was determined by sending it to 10 medical ethics experts and by reviewing their opinions, CVI estimated equal to $89 \%$, and based on their opinions, the necessary changes were applied in the questionnaire. The tool's reliability was assessed by implementing the internal consistency coefficient.

According to the data achieved from 20 physicians, its' Cronbach's alpha and test-retest reliability equaled to $0.92(\mathrm{P}<0.01)$ and 0.86, respectively. Each question has three response options ( $\mathrm{a}, \mathrm{b}, \& \mathrm{c}$ ). The scoring system was as follows: from 1 to 10 , and 21 to $30, a=2, b=1$, $\mathrm{c}=0$, and from question 11 to 20 , and 31 to $40, \mathrm{a}=0, \mathrm{~b}=1$, $\mathrm{c}=2$; where 0 means no skills and 2 indicates a good skill level for each item. The range of scores varied between 0 and 20 for each domain. Finally, after completing the questionnaires, the collected information was coded and entered into Excel software and analyzed by SPSS.

\section{Results}

In total, 80 students with a mean age of 25 years and 80 dentists with a mean age of 45 years participated in this study. Moreover, $58.8 \%$ of the study participants were female and $41.3 \%$ were male.

The findings of each 4 domains are explained in details, as follows: In the moral sensitivity domain, the mean score of dental students was equal to 5.5, the dentists' mean score was calculated as 3.87 and the mean score of the total sample was obtained as 4.6 (Table 1). This mean score is lower than the assumed average value (average score of subscale $=10$ ); thus, the score of the examined categories is less than the average. Considering the value of $t$ and $\mathrm{P} \leq 0.05$, with $95 \%$ confidence, these differences were significant. Additionally, given that the experimental mean value is smaller than the as- sumed one, the ethical observance in dentistry is low in the moral sensitivity domain.

Dental students dentists, and the total study sample, respectively achieved mean scores of 13.92, 15.4, and 14.66 in the ethical reasoning domain. This mean value is greater than the assumed one (average subscale score $=10$ ); therefore, the score of the examined categories was more than the average. In addition, considering the value of $t$ and $\mathrm{P} \leq 0.05$, with $95 \%$ confidence, this difference was significant. Considering that the experimental average value was larger than the assumed one, the observance of professional ethics in the moral reasoning domain was high among the studied subjects (Table 1).

In the moral integrity domain, the mean scores of dental students, dentists, and all samples were calculated as $6.4,5.78$, and 6.09 , respectively. Since this average was lower than the assumed one (average subscale score $=10$ ), the score of the explored categories was less than the average. Considering the value of $t$ and $P \leq 0.05$, it can be said with $95 \%$ confidence that this difference is significant, and given the fact that experimental means is smaller than the assumed mean, it can be deduced that the ethical observance in dentistry is low in moral integrity domain (Table 1 ).

As Table 1 indicates, the mean score of dental students, dentists, and total sample were 13.47, 13.62, and 13.55 , respectively. This means the score was greater than the assumed one (average subscale score $=10$ ); thus, the score of the categories examined was higher than the average. Besides, considering the value of $t$ and $\mathrm{P} \leq 0.05$, with $95 \%$ confidence, this difference was statistically significant. Given that the experimental average was higher than the assumed one; the observance of professional ethics in dentistry was high in the moral courage domain. Kolmogorov-Smirnov and ShapiroWilk tests were used to assess the normal distribution of data. Accordingly, the values obtained for this test was not significant at the confidence level of 0.05 ; therefore, the condition for the normal distribution of the data was observed. Consequently, we could use a parametric test to investigate the research hypotheses. The results of this test are presented in Table 1.

To inferentially analyze the research variables per domain, a one-sample t-test was used. Accordingly, the experimental average value was compared with the assumed one (i.e., the middle number of each subscale or domain; equal to 10). 
Table 1. Status of moral skills in the 4 domains in the studied target groups

\begin{tabular}{|c|c|c|c|c|c|c|c|}
\hline \multirow{2}{*}{$\begin{array}{l}\text { Moral Skill } \\
\text { Domains }\end{array}$} & \multirow{2}{*}{ Variables } & \multicolumn{3}{|c|}{ Assumed mean=10 } & \multicolumn{3}{|c|}{ t-test } \\
\hline & & $\mathbf{N}$ & Experimental Mean & SD & $\mathbf{t}$ & df & $\mathbf{P}$ \\
\hline \multirow{3}{*}{ Moral sensitivity } & Students & 80 & 5.5000 & 3.64223 & -11.051 & 79 & 0.001 \\
\hline & Dentists & 80 & 3.8750 & 2.22969 & -24.570 & 79 & 0.001 \\
\hline & Total & 160 & 4.6875 & 3.11859 & -21.548 & 159 & 0.001 \\
\hline \multirow{3}{*}{ Moral reasoning } & Students & 80 & 13.9250 & 2.35880 & 14.883 & 79 & 0.001 \\
\hline & Dentists & 80 & 15.4000 & 2.11445 & 22.842 & 79 & 0.001 \\
\hline & Total & 160 & 14.6625 & 2.35227 & 25.072 & 159 & 0.001 \\
\hline \multirow{3}{*}{ Moral integrity } & Students & 80 & 6.4000 & 3.24369 & -9.927 & 79 & 0.001 \\
\hline & Dentists & 80 & 5.7875 & 2.72677 & -13.818 & 79 & 0.001 \\
\hline & Total & 160 & 6.0938 & 3.00272 & -16.455 & 159 & 0.001 \\
\hline \multirow{3}{*}{ Moral courage } & Students & 80 & 13.4750 & 3.10155 & 10.021 & 79 & 0.001 \\
\hline & Dentists & 80 & 13.6250 & 2.96552 & 10.933 & 79 & 0.001 \\
\hline & Total & 160 & 13.5500 & 3.02568 & 14.841 & 159 & 0.001 \\
\hline
\end{tabular}

A one-sample t-test was used to determine the general status of ethical skills in the field of dentistry. Therefore, the experimental average value was compared with the assumed one (i.e., the mean number of the examined scale; equal to 40). This average score is lower than the assumed one (average score of the scale $=40$ ). Therefore, the score of the examined categories was less than the average. Considering the value of $\mathrm{t}$ and $\mathrm{P} \leq 0.05$, with $95 \%$ confidence, this difference was statistically significant. Besides, the experimental mean score was smaller than the assumed one; thus, the ethical observance was poor in dentistry students and experts (Table 3 ).
To investigate the differences in observing ethical skills between students and dentists, the Independent Samples t-test was used. The assumption of homogeneity of variance of the two groups was evaluated using the Levene's test. Moreover, the F value of Levene's test was not significant at $\alpha=0.05$; therefore, the assumption of homogeneity of variance and the regression slope was established (Table 4).

There was a significant difference in ethical skills between the explored students and dentists in moral sensitivity and moral reasoning domains. Moreover, the observance of professional ethics in moral sensitivity

Table 2. The normality of distribution of dataset using the Kolmogorov-Smirnov test for each variable

\begin{tabular}{ccc}
\hline Variables & \multicolumn{2}{c}{ Kolmogorov-Smirnov Test } \\
\cline { 2 - 3 } Sig. & D (KS test) & 0.684 \\
\hline Moral sensitivity & 0.716 & 0.102 \\
\hline Moral reasoning & 1.086 & \\
Moral courage & & \\
Total & & \\
\hline
\end{tabular}


Table 3. Assessment of professional ethics in dentistry

\begin{tabular}{ccccccc}
\hline \multirow{2}{*}{ Variables } & \multicolumn{3}{c}{ Hypothetical Mean=40 } & \multicolumn{2}{c}{ t-test } \\
\cline { 2 - 7 } & $\mathbf{N}$ & Experimental Mean & SD & $\mathbf{t}$ & $\mathbf{d f}$ & Sig. \\
\hline Students & 80 & 39.3000 & 4.50990 & -1.388 & 79 & 0.169 \\
Dentists & 80 & 38.6875 & 4.48512 & -2.617 & 79 & 0.011 \\
Total & 160 & 38.9938 & 4.49388 & -2.832 & 158 & 0.005 \\
\hline
\end{tabular}

Table 4. Results of Independent Samples t-test to compare the observance of ethical skills in the field of dentistry between dentistry students of Shahid Beheshti University of Medical Sciences and dentists

\begin{tabular}{|c|c|c|c|c|c|}
\hline Variables & Levene-s test & Significance level & $\mathbf{t}$ & df & Significance level \\
\hline Moral sensitivity & 2.878 & 0.085 & 3.403 & 158 & 0.001 \\
\hline Moral reasoning & 0.069 & 0.794 & -4.165 & 158 & 0.000 \\
\hline Moral integrity & 2.453 & 0.056 & 1.293 & 158 & 0.198 \\
\hline Moral courage & 1.339 & 0.249 & -0.313 & 158 & 0.755 \\
\hline Total & 0.300 & 0.584 & 0.861 & 158 & 0.390 \\
\hline
\end{tabular}

domain was higher (5.5) in the studied dentistry students, compared to the dentists (3.87). Also, the value of the ethical skill in moral reasoning domain was higher among the investigated dentists (15.4), compared with the dental students (13.92).

Moreover, the t-value in the moral integrity domain $(t=1.293)$, moral courage $(t=-0.313)$, and total score of professional ethics $(\mathrm{t}=0.584)$ were not statistically significant $(\mathrm{P} \leq 0.05)$ (Table 4). Therefore, the research hypothesis (the difference between the two independent mean scores) was rejected; there was also no significant difference between the ethical skills in the field of dentistry between the students and experts in ethical integrity and moral courage domains, as well as the total score of professional ethics.

\section{Discussion}

Different societies follow various approaches of professional ethics, which originate from their ethical and religious perspective. The Chambers questionnaire, with emphasis on Rest's principles, introduces a novel approach in understanding the ethical skills in dentistry. In the moral sensitivity domain, the collected mean scores indicated that students presented better ethical skills, compared to the explored dentists; although the mean score of both groups was not satisfactory and ranged lower than average. A similar article reported that the moral sensitivity score of dentistry students of Shahed University in Tehran City was better than the other three domains [8], i.e., consistent with the present research findings. Results of another study on the moral sensitivity of nursing students in South Korea indicated that students registered in the final years of the program achieved higher scores than the first-year students [9]. The reason could be the fact that students become more familiar with ethical issues, compared to the dentists and might receive further supervision on ethical aspects. However, a similar study on nursing students and nurses in service revealed no significant difference between the two groups [10].

Another study was conducted in Japan by Akabayashi and colleagues; the moral sensitivity of the 6th-year dentistry students and new graduates was less than that of the junior students [11]. This finding was consistent with our study in terms of dentists. It could be due to the lack of supervision on the graduates. Possibly, after graduation, they might have no opportunity to review the university lessons, and there is no need to review ethical concepts during the training period; thus, they forget most of the lessons. Nejdsarvari and Bazmi also highlighted the importance of ethical courses. Results of this study on 231 physicians working in hospitals affiliated to Tehran University of Medical Sciences indicated that 
participation in medical ethics courses had increased the moral sensitivity of physicians [12].

This study suggested that the explored dentists obtained higher mean scores in the moral reasoning domain, compared with students. However, students also obtained higher scores in this domain, compared with the other three domains, i.e., beyond expectations. Newell et al. investigated oral hygienists and students. They concluded that they were reasonably well-matched in a high level of moral reasoning [13], i.e., consistent with our findings. Therefore, we could be hopeful that the investigated students have a satisfactory knowledge to overcome the ethical challenges during work. Strict professors, visiting numerous patients in the clinic, and permitting the students to make the final decision in practical work may be considered as the reason for the high score in this domain. However, investigating students at Shahed University in Tehran suggested a lower mean score of this domain, compared to the other domains [8]. Fernando Torres Kavalovski considered the poor ethical reasoning of Brazilian dentistry students as a problem that poses a threat to their future work as dentists [14]. Japanese students achieved low scores in this domain, without significant differences between general medicine students and residents [11].

Data on moral integrity and moral courage were scarce. According to our study findings, moral integrity scores were lower than the average in students and dentists. Afshar et al. argued that the moral integrity score was lower than the ideal level in dentistry students [8], i.e., consistent with our findings. It seems that the dentistry group is unable to prioritize the competition between personal values and professional work. It may be due to an inadequate monitoring system; the lack of the consolidation of ethical principles in work, and the inappropriate proportion of the frequency of patients to the number of dentists in the public centers. Therefore, there exists a better relationship in private centers, in this area.

A study was conducted at the American College of Medicine in January 2011. The relevant data suggested that the concept of personality development, as part of medical education received extensive support. Moreover, positive feedback was obtained from students for their development [15]. It highlights the importance of students' participation in discussions and the workplace situations, a challenging condition that makes the student select and create ethical integrity. A factor causing the lack of appropriate ethical integrity in some individuals is the lack of their character development.
In addition, in this research, the total score of moral courage was higher than the average and was higher in dentists, compared with students. Low levels of moral courage were reported in similar studies on Australian students [16] and dentistry students of Shahed University of Medical Sciences in Iran [8]. Moral courage is the ability to cope with unethical issues that arise while visiting a patient. On one hand, it depends on the individual's personality and moral values, and the extent to which these principles are part of his/her beliefs; on the other hand, it reflects the strength level of his/her inner motivation to cope with unethical issues. Employing personality interviews when selecting students in medical fields could be helpful. This is because some moral skills are linked to a morally-developed personality. However, not everyone is trained about ethical courage. A physician who is under pressure and cannot make the right decision reflects his weakness in this domain [5]. It would be better to advise the last-year students about the correct reaction when encountering a difficult situation, then make the ultimately decision. It seems that dentists encounter the same situation more often and have years of experience; thus, they could better succeed in this regard. Moreover, a study was conducted at the Ahwaz University of Medical Science, in Iran. The relevant results indicated that graduates understood the importance of ethical principles and courses more than students. Besides, having more experience in facing legal and ethical issues in this field was considered as the reason for these skills by the researcher [17]. Given the limited information level in this area, it seems that the employed questionnaire in this research should be explored in other populations and larger groups.

\section{Conclusion}

According to the findings, in two groups of students and dentists, the mean scores of moral reasoning and moral courage domain were higher than the average. Furthermore, the mean scores of moral sensitivity and moral integrity domains were lower than the average. However, the total score of 4 domains of professional ethics was low in the field of dentistry. Thus, we must try to plan for these domains; e.g., empowering in-service dentists by holding practical workshops that present cases and challenge them.

Pine and Mc Goldrick considered a teaching method in which students are provided with theoretical data, i.e., effective in the short-term [18]. In other studies, the intense curriculum of the dentistry program has been introduced as the reason for students' lack of opportunity to learn ethical skills $[19,20]$. Therefore, audiovisual meth- 
ods could be used to teach professional ethical skills as an effective method in dentistry education. Simulated models, team-based scenarios, and group discussions have also been considered [21]. Distributing free brochures about professional ethics in dentistry conferences and holding compulsory courses with retraining points are also suggested. Accordingly, every year, each dentist must have received a few points from active participation in the congresses of ethics along with the retraining points received from other domains; all could be effective approaches.

Regarding impactful training and the evaluation of students, emphasizing on the syllabus of medical ethics courses and holding practical workshops, appointing professors for teaching these courses with an appropriate rapport with patients are all effective [22]. Yoshida argued that most communication skills training is taught in the form of lectures and passive learning that need to be changed [23]. There should be an ethical atmosphere in the universities to motivate the students. Additionally, practical work should be prioritized based on ethical skills. Students' familiarity with the successful experiences of other countries and increasing the related courses could also be helpful. In short, in dentistry educational programs, there are no separate and regular education packages about communication and moral skills and their teaching methods [24]. It is recommended to conduct such studies among dentists in several large cities and other university students.

\section{Ethical Considerations}

\section{Compliance with ethical guidelines}

All ethical principles are considered in this article. The participants were informed about the purpose of the research and its implementation stages; they were also assured about the confidentiality of their information; moreover, they were free to leave the study whenever they wished, and if desired, the research results would be available to them.

\section{Funding}

This research did not receive any grant from funding agencies in the public, commercial, or non-profit sectors.

\section{Authors' contributions}

Both authors were equally contributed in preparing this article.

\section{Conflict of interest}

The authors declared no conflicts of interest.

\section{Acknowledgements}

The authors would like to express their appreciation to all the dentists and dentistry students practicing in this project, the clinic staff of Shahid Beheshti University Dental School who helped us in data gathering and $\mathrm{Mr}$. Sbari who helped us in data analysis.

\section{References}

[1] Ghobadifar MA, Mosalanejad L. [Evaluation of staff adherence to professionalism in Jahrom University of Medical Sciences (Persian)]. Education \& Ethic In Nursing. 2013; 2(2):1-7.

[2] Moberg Dennis J, Seabright, Mark A. The development of moral imagination. Business Ethics Quarterly. 2000; 10(4):84584. [DOI:10.2307/3857836]

[3] Banihashemi A, Sanatkhani M, Mortazavi H. [Investigating the commitment of dentists in mashhad regarding medical-pharmaceutical records of patients (Persian)]. Journal of Mashhad Dent Sch. 2004; 28(1-2):9-14.

[4] Chambers DW. Developing a self-scoring comprehensive instrument to measure rest's four-component model of moral behavior: The moral skills inventory. J Dent Educ. 2011; 75(1):23-35. [ [DOI:10.1002/j.0022-0337.2011.75.1.tb05019.x] [PMID]

[5] Laila M. Developing rest's model to examine the relationship between ethical accounting education and International Education Standard 4(IES 4) Principles. Int J Bus Social Sci. 2015; 6(11):8-17.

[6] Di Y, Bebeau MJ. The independence of James Rest's components of morality: Evidence from a professional ethics curriculum study. Ethics Educ. 2013; 8(3):202-16 [DOI:10.1080/1 7449642.2013.846059]

[7] Moosavi SS, Borhani F, Abbaszadeh A. [The moral courage of nurses employed in hospitals affiliated to Shahid Beheshti University of Medical Sciences (Persian)]. Hayat. 2016; 22(4): 339-49.

[8] Afshar L, Rezvani G, Hosseinzadeh M, Samavatiyan Z. Evaluation of moral skills of undergraduate dental students at Shahed University using a questionnaire. Bioethics J. 2017; 7(24): 47-54.

[9] Park M, Kjervik D, Crandell J, Oermann MH. The relationship of ethics education to moral sensitivity and moral reasoning skills of nursing students. J Nurs Ethics. 2012; 19(4): 568-80. [DOI:10.1177/0969733011433922] [PMID]

[10] Borhani F, Abbaszadeh A, Mohsenpour M. [Illumination meaning of ethical sensitivity in nursing students: A qualitative study (Persian)]. Med Ethics J. 2013; 7(22):93-115. 
[11] Akabayashi A, Slingsby BT, Kai I, Nishimura T, Yamagishi A. The development of a brief and objective method for evaluating moral sensitivity and reasoning in medical students. BMC Med Ethics. 2004; 5(1). [DOI:10.1186/1472-6939-5-1]

[12] Nejadsarvari N, Abbasi M, Borhani F, Ebrahimi A, Rasooli $\mathrm{H}$, KalantarMotamedi $\mathrm{H}$, et al. Relationship of moral sensitivity and distress among physicians. Trauma Mon. 2015, 20(2): e26075. PMC4538732. [DOI:10.5812/traumamon.26075] [PMID] [PMCID]

[13] Newell KJ, Young LJ, Yamoor CM. Moral reasoning in dental hygiene students. J Dent Educ. 1985; 49(2):79-84. [PMID]

[14] de Freitas SF, Kovaleski DF, Boing AF, de Oliveira WF. Stages of moral development among Brazilian dental students. J Dent Educ. 2006; 70(3):296-306. [DOI:10.1002/j.00220337.2006.70.3.tb04086.x] [PMID]

[15] Lantz MS, Bebeau MJ, Zarkowski P. The status of ethics teaching and learning in U.S. dental schools. J Dent Educ. 2011; 75(10):1295-309. [DOI:10.1002/j.0022-0337.2011.75.10. tb05174.x] [PMID]

[16] Bickhoff L, Sinclair PM, Tracy Levett-Jones. Moral courage in undergraduate nursingstudents: A literature review. Collegian. 2017; 24(1):71-83. [DOI: 10.1016/j.colegn.2015.08.002]

[17] Debae A, Saadat N, Qadakzadeh S. Attitudes of medical students and graduates to each medical ethics education in Ahwaz University of Medical Sciences 86-85. Med Ethics. 2009; 3(7):139-11

[18] Pine CM, McGoldrick PM. Application of behavioural sciences teaching by UK dental undergraduates. Eur J Dent Educ. 2000; 4(2):49-56 [DOI:10.1034/j.1600-0579.2000.040201.x] [PMID]

[19] Bertolami CN. Why our ethics curricula don't work. J Dent Educ. 2004; 68(4):414-25. [DOI:10.1002/j.00220337.2004.68.4.tb03758.x] [PMID]

[20] Curriculum guidelines for behavioral science. Section on Behavioral Sciences of the American Association of Dental Schools. J Dent Educ 1993; 57(8):648-57. [PMID]

[21] Maguire P, Fairbairn S, Fletcher C. Consultation skills of young doctors: I--Benefits of feedback training ininterviewing as students persist. Br Med J (Clin Res Ed). 1986; 292(6535): 1573-6. [DOI:10.1136/bmj.292.6535.1573] [PMID] [PMCID]

[22] Karamporian A , Imani B , Torkzaban P. [The attitude of faculty members towards professional ethics at Hamadan University School of Dentistry (Persian)]. J Res Dent Sci. 2013; 10(1):43-51.http://jrds.ir/article-1-295-fa.html

[23] Yoshida T, Milgrom P, Coldwell S. How do U.S. and Canadian dental schools teach interpersonal communication skills? J Dent Educ. 2002; 66(11):1281-8. [DOI:10.1002 /j.0022-0337.2002.66.11.tb03602.x] [PMID]

[24] Jabbarifa RSE, KhalifaSoltani FS, Hosseinpour K, et al. [Evaluation of under- and post-graduate Dental students of Isfahan Faculty of Dentistry in relation to communication skills and professional ethics, Journal of Isfahan Dental School (Persian)]. 2012; 7(5-Special Issue on Materials and Techniques in Dentistry):770-6. 